R. Brown, $A$. nilotica DeCaisne, $A$. filiculoides Lamarck, $A$. microphylla Kaulfuss, $A$. caroliniana Willdenow, and $A$. mexicana Presl has a distinctive perine structure suitable for species recognition. One California population examined, thought to be A. filiculoides, had a perine structure unlike any of the 6 recognised species. Its perine partially resembled that of $A$. filiculoides var. rubra (R. Br.) Strasburger distally and that of $A$. microphylla laterally, as well as having some unique structural features. $A$. mexican $a$ and $A$. caroliniana, recently considered by some as the same species, have distinctly different perine structures, and on this basis, both taxa seem as deserving of species status as do A. filiculoides and A. microphylla. The authors are grateful to Drs Diara, Kaplan, Kulasooriya, Rains, Talley, Warne and Watanabe for providing collections of sporulating Azolla.

This study was supported by NSF grants PCM-8100084 and PCM-8208458.

\title{
Perispore morphology in the Aspleniaceae
}

\section{R. L. L. Viane}

Botanical Institute, K. L. Ledeganckstr. 35, B.9000 Gent, Belgium

Perispore morphology in the Aspleniaceae is reviewed, and the following conclusions derived.

1. Similar perispore patterns have evolved independently in several groups within the family.

2. Perispore patterns change gradually by minor modifications of the perispore layers.

3. There are no sharp boundaries between perisporal-'types'.

4. Perispore patterns in the 'satellite' genera are not different from patterns within Asplenium sensu stricto.

5. Perispore characters used with care and together with other characters may prove to be important in tracing phylogenetic relationships within this family.

\section{Perispore morphology in New Guinea Aspleniaceae}

\author{
R. J. Johns
}

P.N.G. University of Technology, Lal, Papua New Guinea

and

\section{G. van Uffelen}

Rijksherbarium, P.O. Box 9514, 2300 RA Leiden, The Netherlands

An investigation was conducted using the SEM into the perispore morphology of 60 species of Asplenium and 5 species of Diplora, to assess its value in constructing 